\title{
New Insights on Glyphosate Mode of Action in Nodular Metabolism: Role of Shikimate Accumulation
}

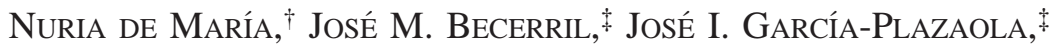 \\ Antonio Hernández, ${ }^{\dagger}$ María R. DE FELIPE, ${ }^{\dagger}$ AND \\ Mercedes Fernández-Pascual $*, \dagger$
}

\begin{abstract}
Department of Plant Physiology and Ecology, Institute for Natural Resources, Centre for
Environmental Sciences, CSIC, Serrano 115-bis, 28006 Madrid, Spain, and Department of Plant

Biology and Ecology, University of the Basque Country/EHU, Apartado 644, E-48080 Bilbao, Spain
\end{abstract}

\begin{abstract}
The short-term effects of the herbicide glyphosate $(1.25-10 \mathrm{mM})$ on the growth, nitrogen fixation, carbohydrate metabolism, and shikimate pathway were investigated in leaves and nodules of nodulated lupine plants. All glyphosate treatments decreased nitrogenase activity rapidly (24 h) after application, even at the lowest and sublethal dose used $(1.25 \mathrm{mM})$. This early effect on nitrogenase could not be related to either damage to nitrogenase components (I and II) or limitation of carbohydrates supplied by the host plant. In fact, further exposure to increasing glyphosate concentrations $(5 \mathrm{mM})$ and greater time after exposure (5 days) decreased nodule starch content and sucrose synthase (SS; EC 2.4.1.13) activity but increased sucrose content within the nodule. These effects were accompanied by a great inhibition of the activity of phosphoenolpyruvate carboxylase (PEPC; EC 4.1.1.31). There were remarkable and rapid effects on the increase of shikimic and protocatechuic (PCA) acids in nodules and leaves after herbicide application. On the basis of the role of shikimic acid and PCA in the regulation of PEPC, as potent competitive inhibitors, this additional effect provoked by glyphosate on 5-enolpyruvylshikimic-3-phosphate synthase enzyme (EPSPS; EC 2.5.1.19) inhibition would divert most PEP into the shikimate pathway, depriving energy substrates to bacteroids to maintain nitrogen fixation. These findings provide a new explanation for the effectiveness of glyphosate as a herbicide in other plant tissues, for the observed differences in tolerance among species or cultivars, and for the transitory effects on glyphosate-resistant transgenic crops under several environmental conditions.
\end{abstract}

KEYWORDS: Glyphosate; herbicide resistance; lupine; nitrogen fixation; PEPC; shikimic acid

\section{INTRODUCTION}

Grain legumes such as lupine (Lupinus albus L.) are considered to have great agronomic potential due to the high seed protein content $(30-50 \%)$ and positive effect on soil fertility (1). However, the presence of weeds decreases the availability of nutrients for legumes, and this may limit nitrogen fixation. The use of environmentally friendly herbicides that do not affect symbiotic nitrogen fixation is desirable, because maintaining this essential global process can be very important for sustainable legume yields. Considering that the most successful transgenic crop in the world is the nitrogen-fixing legume soybean made resistant to the herbicide glyphosate (2), understanding of the full impacts of glyphosate on nitrogen fixation is needed. Crops engineered for resistance to glyphosate are economical and have become an important tool for weed management (3). Understanding of the effects of this herbicide

* Corresponding author (telephone 34917452500; fax 34915640800; e-mail mfernandezp@ccma.csic.es).

$\dagger$ CSIC.

$\ddagger$ University of the Basque Country/EHU. in a complex system such as legume-Rhizobium symbiosis (4) is important. Previous works on the effects of several herbicides on the symbiosis Lupinus albus-Bradyrhizobium sp. (Lupinus) have been carried out (5), but not with glyphosate.

Glyphosate [ $N$-(phosphonomethyl)glycine], the active ingredient of the herbicide Roundup (Monsanto, St. Louis, MO) and other commercial herbicides, is a broad-spectrum, nonselective herbicide largely used during the past three decades with very low adverse environmental effects (6). Glyphosate is rapidly transported through the phloem to metabolic sinks such as soybean grain (7) and nodules (8). Glyphosate inhibits specifically the enzyme 5-enolpyruvylshikimic-3-phosphate synthase (EPSPS), causing a reduction of the biosynthesis of aromatic amino acids (tryptophan, tyrosine, and phenylalanine) and the accumulation of shikimic acid and some hydroxybenzoic acids in leaves and other organs $(9-11)$. Traditionally, the toxic effects of glyphosate have been related with blockage of aromatic amino acids synthesis, drain of intermediates from other essential pathways to the shikimate pathway, and toxicity of intermediates of shikimate pathway, but there is not a full 
picture of the sequence of metabolic disturbances in plants after EPSPS inhibition.

The effects of glyphosate on nitrogen fixation are not fully understood. Most of these studies have been carried out on soybean and have been recently reviewed by Zablotowicz and Reddy (4) in glyphosate-resistant and nonresistant cultivars. These studies indicated an inhibition of nitrogen fixation on glyphosate-resistant cultivars under some conditions of nodule development (8), a great inhibition of nitrogen fixation in nonresistant cultivars $(10,12)$, and an accumulation of intermediates of the shikimate pathway in free-living Bradyrhizobium japonicum forms $(10,13)$ and in nodules $(10)$. Although in glyphosate-resistant soybean the initial decrease on nitrogen fixation recovered $(4,12)$, this is not the case of nonresistant cultivars or of the resistant cultivars under water stress (12).

Biological nitrogen fixation is totally dependent on the import and metabolism of carbon skeletons into the nodule. Phosphoenolpyruvate (PEP) is one of the initial substrates for the shikimate pathway and other important pathways as oxaloacetate production in $\mathrm{C}_{4}, \mathrm{CAM}$, and $\mathrm{C}_{3}$ plants. This reaction is catalyzed by phosphoenolpyruvate carboxylase (PEPC), a ubiquitous photosynthetic and anaplerotic enzyme in higher plants, that plays also a central role in the carbon metabolism in symbiotic root nodules: supplying energy sources to bacteroids; supplying the carbon skeleton for the assimilation of fixed nitrogen; and recycling $\mathrm{CO}_{2}$ generated through respiration in both plant cells and bacteroids. This enzyme is regulated in plants by allosteric inhibition of L-malate and the intermediate of shikimic acid pathway, shikimate $(14,15)$.

In this study we investigated the early effects of glyphosate on several parameters related with nitrogen fixation, analyzing the disturbance on carbon metabolism and shikimate pathway of nodules. This initial disturbance can cause other side effects interfering with regulation of an essential enzyme such as PEPC. This new approach could help to explain the unique mode of action and toxicity exhibited by this herbicide and could have important consequences in the understanding of the phytotoxic effects in nodules and other plant organs, side effects on glyphosate-resistant crops, and relative tolerance among group species $\left(\mathrm{C}_{4}, \mathrm{CAM}\right.$, and $\left.\mathrm{C}_{3}\right)$.

\section{MATERIALS AND METHODS}

Plant Material, Experimental Design, and Herbicide Treatments. Lupinus albus L. cv. Multolupa seeds (La Higueruela, Santa Olalla, Toledo, Spain) were surface sterilized in $0.1 \% \mathrm{HgCl}_{2}$ for $5 \mathrm{~min}$ and then washed several times with sterile distilled water. Seeds were sown in $1 \mathrm{~L}$ pots filled with vermiculite and watered with nitrogen-free nutrient solution according to the method of Lang et al. (16). The plants were inoculated twice (first at sowing and then 1 week later) with 1 $\mathrm{mL}\left(10^{8}\right.$ cells $\left./ \mathrm{mL}\right)$ of a suspension Bradyrhizobium sp. (Lupinus) strain ISLU16 (CIFA, Sevilla, Spain). Plants were grown in a growth chamber at $25 / 15{ }^{\circ} \mathrm{C}$ (day/night) temperature, $60-70 \%$ relative humidity, and $16 \mathrm{~h}$ at $190 \mu \mathrm{mol} \mathrm{m}{ }^{-2} \mathrm{~s}^{-1}$ photosynthetic photon flux density. When plants were 5 weeks old, each plant was sprayed with $2 \mathrm{~mL}$ of a solution with $0,1.25,2.5,5$, or $10 \mathrm{mM}$ glyphosate (isopropylamine salt) with $0.1 \%$ Triton X-100, by using a $100 \mathrm{~mL}$ sprayer (Symta, S.A.L., Spain). Nodules and leaves were harvested at 1,2, 3, 4, 5, and 7 days after herbicide application. Leaves and nodules were immediately frozen in liquid nitrogen and stored at $-80{ }^{\circ} \mathrm{C}$.

Analytical Methods. Nitrogenase Activity. Nitrogen fixation was measured as acetylene reduction activity (ARA) on nodulated roots following the method described in Fernández-Pascual et al. (5).

Isolation of Bacteroids. Bacteroids were isolated from $1 \mathrm{~g}$ of nodules by homogenization in a mortar with $5 \mathrm{~mL}$ of $50 \mathrm{mM}$ potassium phosphate buffer, $\mathrm{pH} 7.5,200 \mathrm{mM}$ sodium ascorbate, and 10\% (w/v) of insoluble polyvinylpyrrolidone (PVPP). The homogenate was initially centrifuged at $250 \mathrm{~g}$ for $5 \mathrm{~min}$ at $4{ }^{\circ} \mathrm{C}$, and later the supernatant was centrifuged at $8000 \mathrm{~g}$ for $10 \mathrm{~min}$ at $4{ }^{\circ} \mathrm{C}$. The pellet, containing bacteroids, was washed twice in $1 \mathrm{~mL}$ of washing solution that contained $50 \mathrm{mM}$ potassium phosphate buffer, $300 \mathrm{mM}$ sucrose, and 2 $\mathrm{mM} \mathrm{MgSO}$. Finally, the bacteroids pellet was suspended in $20 \mathrm{mM}$ potassium phosphate buffer, $5 \mathrm{mM} \mathrm{MgCl}, 1 \mathrm{mM}$ ethylenediaminetetraacetic acid (EDTA), $1 \mathrm{M}$ glycerol, and $1 \mathrm{mM}$ dithiothreitol (DTT) and sonicated. Bacteroids were disrupted by sonication with eight pulses of $40 \mathrm{~s}$ and 50\% intensity, using a Vibrate-Cell model VC-375 (Sonics and Materials Inc., Newtown, CT). Lysis of bacteroids was verified by light microscopy. Finally, samples were centrifuged at $15000 \mathrm{~g}$ for 15 min at $4{ }^{\circ} \mathrm{C}$. Protein content was estimated in the supernatant, according to the Bradford assay (Bio-Rad, Hercules, CA) using bovine serum albumin as a standard.

Protein Extraction and Immunoblotting. The extraction of proteins was performed according the method of Fernandez-Pascual et al. (5). Proteins were separated by sodium dodecyl sulfate-polyacrylamide gel electrophoresis (SDS-PAGE), using denaturing 12.5\% acrylamide gels. Electroblotting of proteins to nitrocellulose sheets was carried for $2 \mathrm{~h}$ at $20 \mathrm{~V}$ in a semidry system (Bio-Rad). Nitrocellulose membranes were incubated in blocking solution [5\% defatted milk powder in sterilized phosphate-buffered saline (PBS), $\mathrm{pH}$ 7.2] for $1 \mathrm{~h}$, followed by overnight incubation in components I and II of the nitrogenase antibody diluted 1:1000 and 1:2000, respectively. The component I antibody from the nitrogenase of Klebsiella was donated by Dr. Imperial (ETSIA, Polytechnic University of Madrid, Spain), and the component II universal antibody was obtained by Dr. Ludden (Department of Biochemistry, University of Wisconsin). After a washing with PBS, the nitrocellulose membrane was incubated in goat anti-rabbit IgG alkaline phosphatase conjugate (Sigma-Aldrich, St. Louis, MO) diluted 1:1000 in PBS for $2 \mathrm{~h}$ at room temperature. After a washing with PBS and TBS, pH 7.4, alkaline phosphatase activity was developed for $10 \mathrm{~min}$ in darkness with $100 \mathrm{mM}$ Tris- $\mathrm{HCl}$, pH 9.6, containing nitroblue tetrazolium $1 \mathrm{mg} / \mathrm{mL}$ in $2 \%$ dimethyl sulfoxide, 5-bromo-4-chloro-3-indolylphosphate $0.05 \mathrm{mg} / \mathrm{mL}$, and $1 \mathrm{mM} \mathrm{MgCl} 2$. The immunoblots were then scanned in the gray-scale mode, and the data were integrated using image-processing software (SigmaScan Pro imaging software, SPSS Science, Chicago, IL).

Starch Content. Nodules were incubated in $80 \%$ ethanol for $3 \mathrm{~min}$ at $100{ }^{\circ} \mathrm{C}$. The excess of ethanol was removed by heating at $50{ }^{\circ} \mathrm{C}$. The pellet was pulverized and resuspended with $40 \mathrm{~mL} / \mathrm{g}$ of distillate water. The sample was boiled for $1 \mathrm{~h}$ and centrifuged $3000 \mathrm{~g}$ for 10 min. The supernatant was used for determinations. Starch was analyzed spectrophotometrically according to the method of Gordon et al. (17).

Sucrose Content. Sucrose extraction and determination were carried out following the method described by Gordon et al. (17).

Shikimate and Hydroxybenzoic Acids Content. Shikimate and hydroxybenzoic acids were extracted from nodules and leaves basically as described by Hernandez et al. (10). The concentrations of shikimate and hydroxybenzoic acids were determined by high-performance liquid chromatography (HPLC) using a Waters (Milford, MA) liquid chromatographic system equipped with two model 510 pumps, a model 717 Plus injector, and a model 996 photodiode array detector and controlled by a computer using Millennium software. Chromatography was performed as described by Hernandez et al. (10).

Sucrose Synthase (SS) Activity. Nodules ( $0.3 \mathrm{~g})$ were homogenized at $4{ }^{\circ} \mathrm{C}$ and extracted with $3 \mathrm{~mL}$ of $50 \mathrm{mM}$ potassium phosphate buffer, pH 8.0, 1 mM EDTA, 20\% ethylene glycol, and 30\% insoluble PVPP. The SS activity was assayed by monitoring the reduction of nicotinamide adenine dinucleotide $\left(\mathrm{NAD}^{+}\right)$. The reaction mixture included 2 $\mathrm{mM}$ uridine diphosphate (UDP), $100 \mathrm{mM}$ sucrose, $1.5 \mathrm{mM} \mathrm{NAD}^{+}$, and 5 units of uridine diphosphate-glucose (UDPG) dehydrogenase in $100 \mathrm{mM}$ bicine- $\mathrm{KOH}(\mathrm{pH} 8.5)$. The reaction volume was $1 \mathrm{~mL}$.

Phosphoenolpiruvate Carboxylase, Malate Dehydrogenase (MDH), and Aspartate Aminotransferase (AAT) Activities. Homogenization of nodules $(0.3 \mathrm{~g})$ was performed as above, using $50 \mathrm{mM}$ Tris- $\mathrm{HCl}, \mathrm{pH}$ 8.0 , containing $10 \mathrm{mM} \mathrm{MgCl}_{2}, 5 \mathrm{mM}$ DTT, and $25 \%$ ethylene glycol as extraction buffer. The activities of PEPC, MDH (EC 1.1.1.37), and AAT (EC 2.6.1.2) were analyzed according to the method of Lang et al. (16). For determination of PEPC activity, $50 \mathrm{mM}$ Tris-HCl, $\mathrm{pH} 8.0$, containing $10 \mathrm{mM} \mathrm{MgCl}$, $5 \mathrm{mM}$ DTT, $10 \mathrm{mM} \mathrm{NaHCO}, 2 \mathrm{mM}$ 

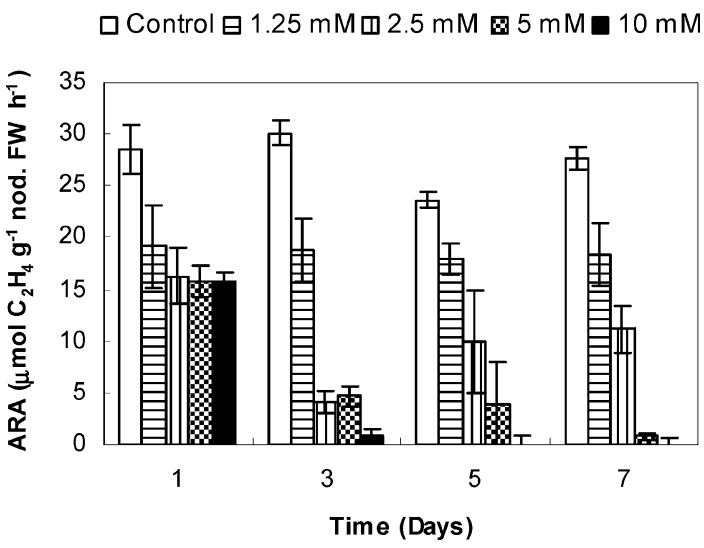

Figure 1. Effect of glyphosate $(0,1.25,2.5,5$, and $10 \mathrm{mM})$ on specific nitrogenase activity, measured as ARA ( $\mu \mathrm{mol}$ of ethylene $\mathrm{g}^{-1}$ of nodule FW $\mathrm{h}^{-1}$ ) in nodules at $1,3,5$, and 7 days after treatment. Each value represents the average \pm SE of eight determinations.

phosphoenolpyruvate, 20 units/mL MDH, and $0.2 \mathrm{mM}$ NADH buffer was used. The reaction was started by adding $0.1 \mathrm{~mL}$ of nodule extract in $1 \mathrm{~mL}$ of volume reaction. Oxidation of NADH was measured at $340 \mathrm{~nm}$ at room temperature every $15 \mathrm{~s}$ for $3 \mathrm{~min}$. To check the sensitivity of PEPC to the accumulated shikimate and protocatechuate caused by glyphosate, we assayed the activity of PEPC from nodules of non-glyphosate-treated plants. The enzyme extract was assayed in the presence of the same concentrations of shikimate or protocatechuic acid (PCA) found in nodules of glyphosate-treated plants. Nodules extract was incubated for 10 min with shikimate solutions $(30,15,8$, $1.5 \mathrm{mM})$ and PCA $(15,10,5 \mathrm{mM})$ and for 20 and 30 min with $15 \mathrm{mM}$ shikimate and $10 \mathrm{mM}$ PCA; afterward, PEPC activity was measured.

Statistical Analyses. Data were analyzed with SPSS program version 11.5.1 by one-way analysis of variance (ANOVA), and significant differences among treatments were determined by LSD with $(P \leq 0.05)$.

\section{RESULTS AND DISCUSSION}

Effects on Growth Parameters and Nitrogenase Activity and Components. The legume nodules are organs optimized for the operation of the symbiosome, an organelle specialized on nitrogen fixation. The functionality of this biological process depends on the host, microsymbiont, and environmental conditions. L. albus-Bradyrhizobium sp. (Lupinus) symbiosis seems to be more tolerant than other legumes to several abiotic stresses $(5,18,19)$ and some herbicides (5). Under our experimental conditions, glyphosate sprayed on leaves produced visual toxicity symptoms on lupine leaves rapidly. Nitrogenase activity, measured as ARA, was rapidly affected; a decrease of $33 \%$ of ARA was detected as soon as $24 \mathrm{~h}$ after glyphosate treatment, even with the lowest dose applied (1.25 mM) (Figure 1). This initial inhibition was not restored in these plants, so after 7 days of treatment with $1.25 \mathrm{mM}$ glyphosate, ARA was $60 \%$ of control values. Higher concentrations of the herbicide greatly affected nitrogenase activity, and it was completely arrested in 3 days with the $10 \mathrm{mM}$ concentration of glyphosate. Nitrogenase activity inhibition by glyphosate has been described in other legumes such as soybean $(4,10)$, and this early inhibition also occurred in a glyphosate-resistant soybean cultivar, but this activity was later recovered (12). Because glyphosate is translocated continuously from leaves to terminal sinks such as the nodule, very high levels of the herbicide in nodules of soybean have been reported (8). However, glyphosate itself induced only a slight inhibition of ARA of bacteroids isolated from untreated soybean plants and incubated directly with the herbicide (10). This result suggests that the inhibitory effect on nitrogenase is probably more related with a metabolic disturbance provoked by the herbicide.

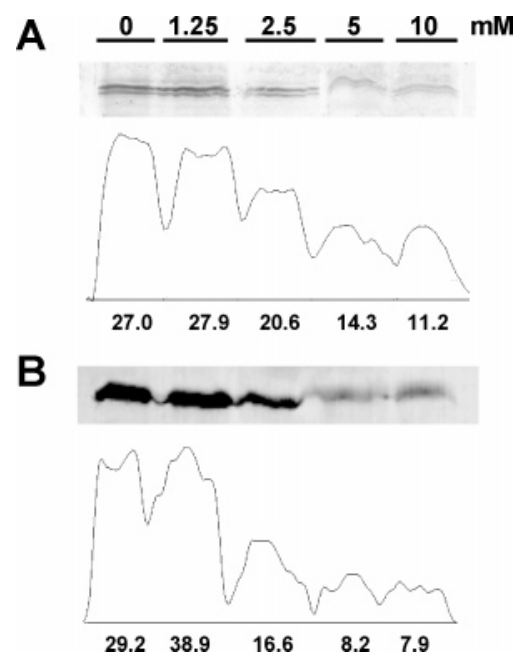

Figure 2. Immunoblot of nitrogenase components from lupine nodules after 4 days of exposure to glyphosate (concentrations as is Figure 1): (A) Western blot analysis of component I ( $35 \mu \mathrm{g}$ of bacteroidal protein was loaded to each line) and densitogram of the relative content for each concentration of herbicide; (B) Western blot analysis of component II (10 $\mu \mathrm{g}$ of bacteroidal protein was loaded) and densitogram of the relative content. Areas under the curve are expressed in arbitrary units.

So far, no studies have been conducted to determine whether the nitrogen fixation decrease caused by glyphosate was due to effects on the components of the enzyme nitrogenase. To address this, we performed a Western blot analysis of nitrogenase components I (MoFe protein) and II (Fe protein). The results in Figure 2 indicate that the enzyme components were affected only at concentrations above $2.5 \mathrm{mM}$ and after 4 days of glyphosate treatment, with component II being more sensitive ( $73 \%$ inhibition) than component I (58\% inhibition) at $10 \mathrm{mM}$. The effects of higher concentrations of the herbicide on nitrogenase were sufficient to eliminate the activity, but were not enough to destroy all of the epitopes recognized by the antibodies. The lack of relationships between nitrogenase activity and detection of nitrogenase components has also been described in lupine nodules under different oxygen concentrations (19). The inability to synthesize aromatic amino acids in the presence of glyphosate can explain the later effect on nitrogenase components. Although the decrease in enzyme content was dose dependent and apparent after 4 days, ARA was initially more affected, even when components I and II were not affected (Figure 1 and 2). This indicated that the early inhibition of this activity was unrelated to other changes associated with nitrogenase turnover.

Nodule Carbohydrate Metabolism. The energy demand for nitrogenase activity in bacteroids is dependent on the host plant for the supply and metabolism of carbohydrates within the nodule. In fact, a decrease in flux of carbon to the nodule causes a decline in nitrogen fixation (20). Glyphosate could be involved in the alteration of nodular metabolism by means of the limitation of carbohydrates from the plant shoot and/or their transformation to carbon substrates for bacteroids. If so, carbohydrate limitation could affect bacteroid respiration and incorporation of fixed nitrogen. However, several lines of evidence indicated that this was not the mechanism involved in the early reduction of nitrogen fixation caused by glyphosate. Our results indicated that treatments below $2.5 \mathrm{mM}$ did not affect starch content, even 7 days after treatment (Figure 3A). However, a starch content decrease in 5 and $10 \mathrm{mM}$ treatments could be observed in 3 days, and it progressed with time, reaching 69 and $75 \%$ inhibitions after 7 days with 5 and 10 
A

口 $0 \mathrm{mM} 1.25 \mathrm{mM} 2.5 \mathrm{mM} 5 \mathrm{mM}-10 \mathrm{mM}$
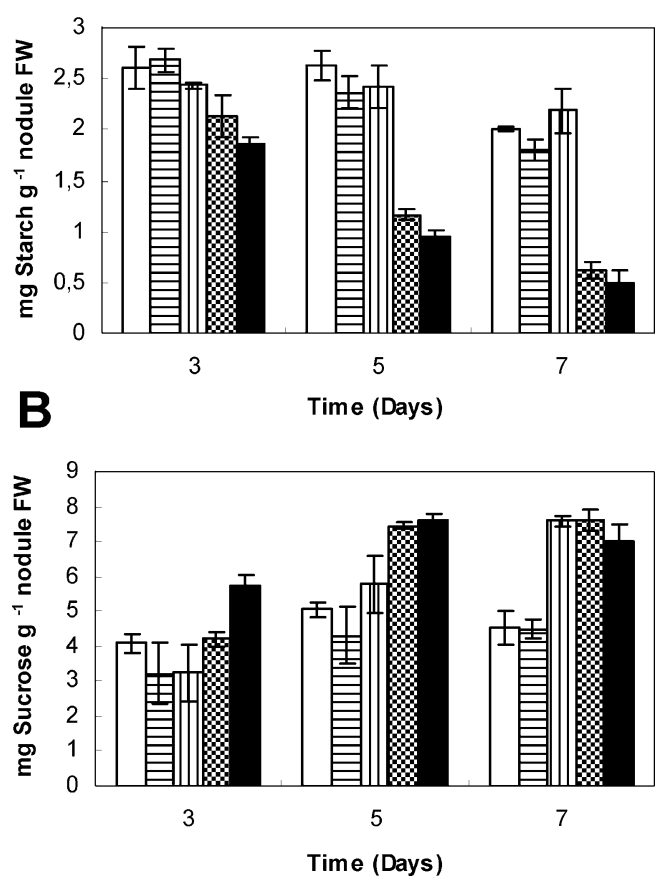

Figure 3. Effect of glyphosate on (A) starch and (B) sucrose contents in nodules from lupine plants 3,5 , and 7 days after treatment. Each value represents the average \pm SE of six determinations.

$\mathrm{mM}$, respectively. Therefore, the nitrogenase activity inhibition preceded the decrease of starch accumulation in lupine nodules. Other authors have also described a severe descent in the accumulation of starch in sugar beet leaves treated with glyphosate (21). These authors indicated that glyphosate induced a depletion of carbon from the photosynthetic carbon reduction cycle, reducing the rate of regeneration of the intermediate ribulose bisphosphate, photosynthesis, and starch synthesis, but the effect on the rate of sucrose synthesis and transport was negligible. In our study, sucrose content in lupine nodules showed an opposite pattern as compared with starch, increasing with time in the presence of glyphosate (Figure 3B). After 3 days, sucrose increased $29 \%$ only with the highest concentration of herbicide, but after 7 days, an increase was observed in all treatments above $2.5 \mathrm{mM}$. A similar response has been observed in sugarcane (22), and this herbicide has been used as a ripener to increase sucrose yield in sugarcane. Because glyphosate does not inhibit sucrose synthesis directly (23) this sugar can be accumulated in plant tissues. Several factors can contribute to increased sucrose levels within the nodules if some of the metabolizing enzymes of sucrose are affected. In mature nodules, sucrose is first metabolized by SS or alkaline invertase (AI, EC 3.2.1.26) because mature nodules do not have AI activity (17). Among them SS is essential for the maintenance of nitrogenase activity, and the loss of SS activity caused cessation of nitrogen fixation in a mutant of pea with SS activity greatly reduced (17). A similar effect has been reported for plants under water stress, provoking a dramatic increase in sucrose content in those nodules $(20,24)$. Glyphosate did not inhibit the activity of sucrose metabolizing enzymes except for a reported inhibition of auxin-mediated acid invertase activity in sugarcane (22). Because mature nodules do not have AI activity (17), sucrose accumulation cannot be related to the inhibition of this enzyme. To date, there are no reports on the effects of glyphosate on nodule sucrose-metabolizing enzymes. The data of Figure 4 indicate that glyphosate provoked an initial

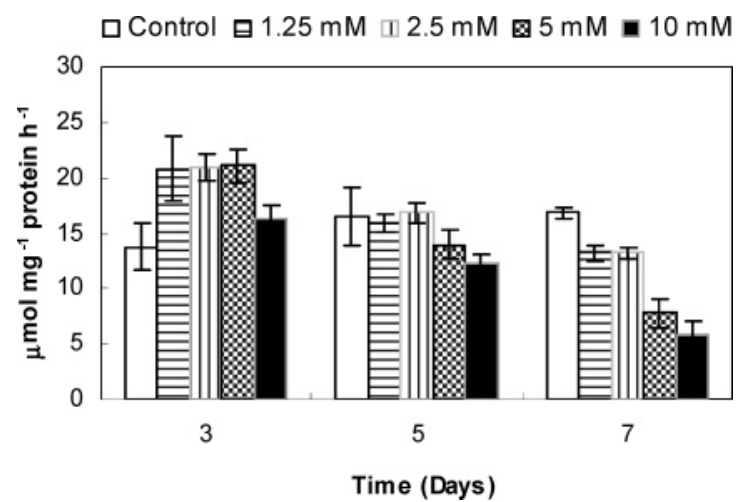

Figure 4. Sucrose synthase activity in nodules from lupine plants treated with glyphosate during 3,5, and 7 days. Each value represents the average \pm SE of six determinations.

increase (3 days) in SS activity and then (5 and 7 days after treatment) the activity was progressively reduced, especially in 5 and $10 \mathrm{mM}$ treatments (53 and $65 \%$ inhibition, respectively). SS activity was also slightly inhibited with the lowest dose of glyphosate, but this effect was significant only 7 days after glyphosate application. Because the accumulation of sucrose (Figure 3B) occurred earlier than the inhibition of the activity of SS (Figure 4), our data indicate that such accumulation was not related with an effect of the main sucrose-metabolizing enzyme in nodules (SS) (17). In addition, SS plays an important role in the reversible conversion of sucrose to starch (25). In agreement with this conversion, SS could also be involved in the synthesis of starch, which could partially explain the decrease of starch levels paralleling the decrease of SS activity at higher glyphosate doses (5 and $10 \mathrm{mM}$ ). From the above, it can be concluded that the availability of sucrose in glyphosate-treated plants did not limit energy requirements for nitrogen fixation in nodules, and, thus, the early inhibition of nitrogenase was unrelated to this requirement. On the other hand, the study of Hernandez et al. (10), on bacteroids isolated from glyphosatetreated soybean, indicated that the ARA of those bacteroids was affected. However, in the same study when isolated bacteroids from nontreated plants were incubated in the presence of succinate and glyphosate, only a slight inhibition of ARA could be observed, even at glyphosate concentrations as high as 10 $\mathrm{mM}$. This low effect of glyphosate in the presence of substrates for bacteroids confirms that glyphosate itself has a limited direct effect on nitrogenase activity and suggests that some limitation on the availability on carbon substrates could occur from sucrose through its conversion to dicarboxylic acids.

Shikimic and Hydroxybenzoic Acids Content. Approximately $20 \%$ of the carbon fixed by plants is normally processed through the shikimic acid pathway (26). After application, glyphosate is readily translocated to metabolic sinks, especially at low application rates (27). Inhibition of EPSPS deregulates the pathway, which results in uncontrolled flow of carbon and subsequent massive accumulation of shikimate and hydroxybenzoic acids in metabolic sinks such as leaves and nodules of legumes $(10,28)$. Our data show that the application of glyphosate to the leaves affected phenolic metabolism in young and mature leaves and in nodules. Although we determined several hydroxybenzoic acids (protocatechuic, gallic, gentisic, 4-hydroxybenzoic, vanillic, and syringic acids), plants treated with glyphosate only accumulate shikimate (Figures $\mathbf{5}$ and 7A) and PCA (Figures 6 and 7B). In leaves of glyphosate-treated plants (both young and mature) shikimic acid increased in parallel with the doses of herbicide applied and time of exposure. Significant differences could be observed from 1 day after 


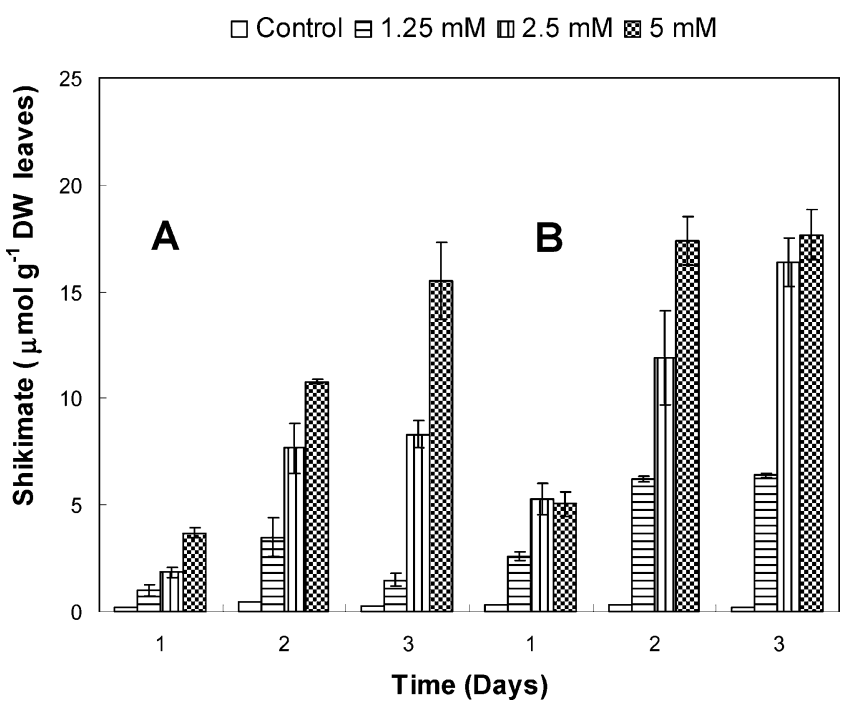

Figure 5. Shikimate content ( $\mu \mathrm{mol} / \mathrm{g}$ of DW) in $(\mathbf{A})$ mature and $(\mathbf{B})$ young leaves of nodulated lupine plants treated with glyphosate. Each value represents the average \pm SE of three to five determinations.

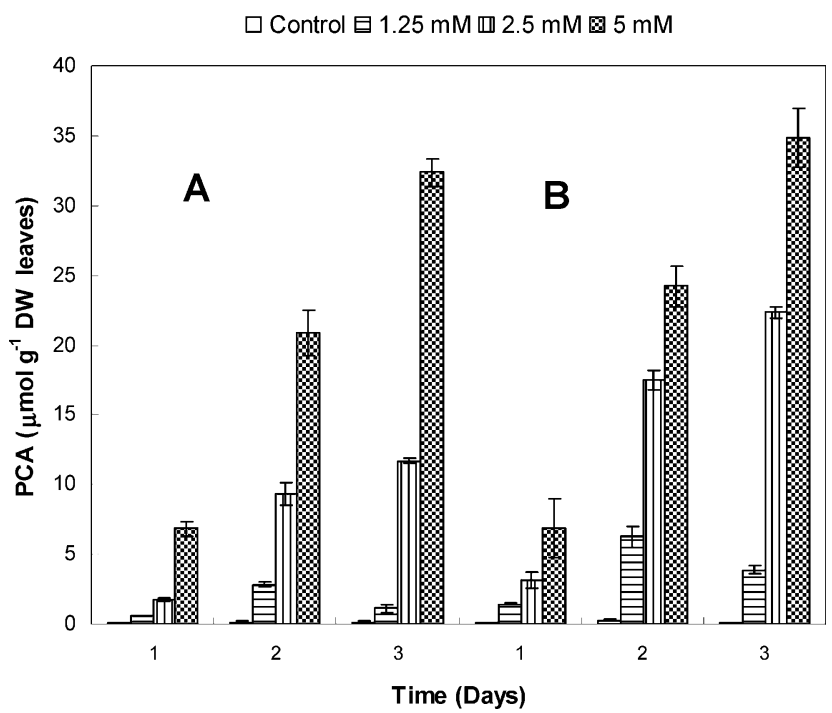

Figure 6. Protocatechuate content $(\mu \mathrm{mol} / \mathrm{g}$ of $\mathrm{DW})$ in $(\mathbf{A})$ mature and (B) young leaves of nodulated lupine plants treated with glyphosate. Each value represents the average \pm SE of three to five determinations.

application with the lower doses used (1.25 mM) (Figure 5). Glyphosate was rapidly translocated from mature leaves to young leaves, so shikimate and PCA concentrations in the latter were higher than those found in mature leaves. Finally, the level of PCA in leaves was 2-fold higher than that of shikimate (Figures 5 and 6).

Our data indicate that glyphosate was also readily translocated from leaves to nodules, as soon as $24 \mathrm{~h}$ after treatment. This effect was apparent as a great increase in the level of shikimate within the nodule on treatments above $2.5 \mathrm{mM}$ (Figure 7A). This accumulation was continuous with time of exposure, so after 3 days the levels of shikimate in nodules of treated plants with 2.5 and $5 \mathrm{mM}$ glyphosate were 20-fold over the background levels. At the lower concentration $(1.25 \mathrm{mM})$ the effect was apparent after $48 \mathrm{~h}$ of treatment and later tended to resume. In fact, shikimate accumulation was the only physiological parameter of nodules, other than nitrogenase activity, affected after $24 \mathrm{~h}$ by glyphosate treatments above $2.5 \mathrm{mM}$. Protocatechuate also accumulated in nodules but to a less extent, later and only at the higher glyphosate doses (Figure 7B). Hernandez et al.

\section{A}

口0 mM 曰 $1.25 \mathrm{mM}$ 口2.5 mM $05 \mathrm{mM}$

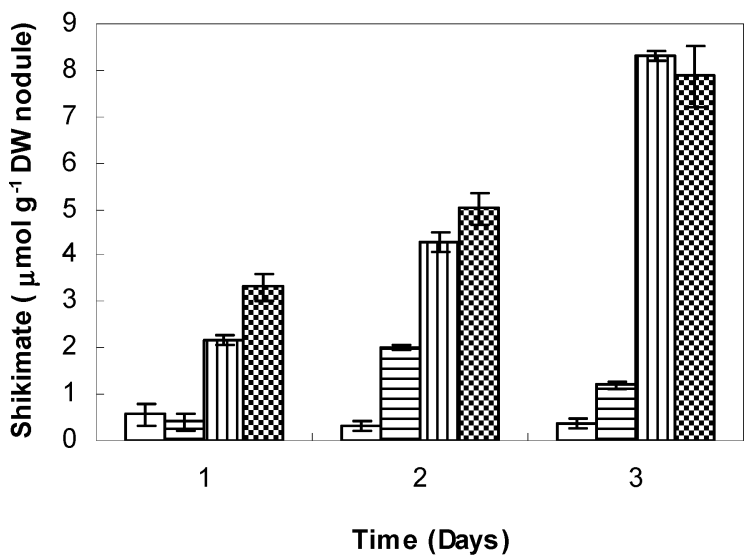

B

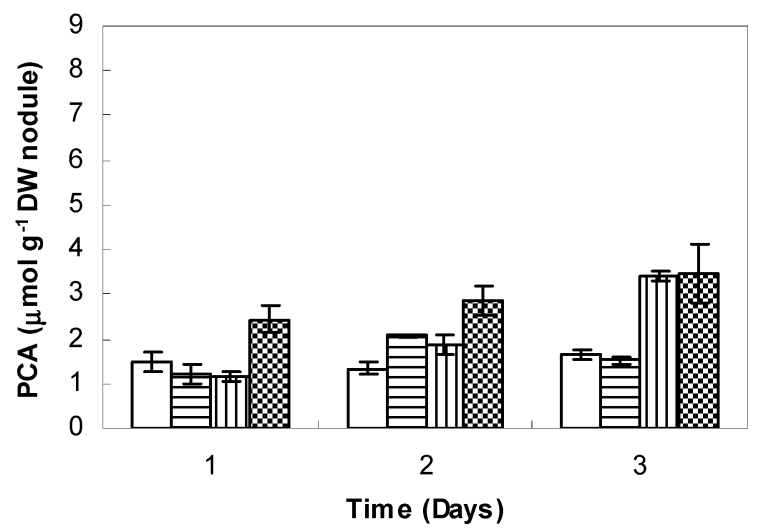

Figure 7. Shikimate $(\mathbf{A})$ and protocatechuate $(\mathbf{B})$ contents $(\mu \mathrm{mol} / \mathrm{g}$ of DW) in nodules from lupine plants treated with glyphosate. Each value represents the average \pm SE of three to five determinations.

(10) also reported some increases in shikimate content in nodules of soybean after 7 days of exposure to glyphosate, but our study is the first report of low rates of applied glyphosate provoking accumulation of shikimate pathway intermediates in nodules in a very short time. The time to determine glyphosate effects on shikimate pathway intermediates is critical, as the level of these metabolites is the balance between synthesis, caused by deregulation of the shikimate pathway, further transformation to other related compounds, and degradation. The level of shikimate after glyphosate application can change with time, as has been observed in plant tissues such as young leaves of velvetleaf (9), wheat kernels of wheat (29), and horseweed leaves (30). The production of the shikimate pathway intermediates in the nodule could cause a drain of carbon skeletons derived from sucrose that could limit their utilization by bacteroids.

PEPC, MDH, and AAT Activities in Nodules. To further evaluate the utilization of carbohydrates on nodules, we measured the activity of several nodular enzymes involved in supplying carbon substrates to bacteroids (PEPC, MDH) or in the assimilation of fixed nitrogen (AAT). The activity of MDH was not initially reduced by glyphosate (Figure 8A), but some inhibition could be observed after 5 and 7 days at doses above $5 \mathrm{mM}$ glyphosate. AAT activity showed a similar pattern, and an inhibition of $44 \%$ was reached after 7 days of exposure (Figure 8B). The activity of the PEPC was inhibited by glyphosate following a dose-dependent response (Figure $\mathbf{8 C}$ ). This inhibitory effect was not observed at $24 \mathrm{~h}$, but after 3 days, 
A

口Control日 $1.25 \mathrm{mM}$ 口 $2.5 \mathrm{mM} \otimes 5 \mathrm{mM} 10 \mathrm{mM}$

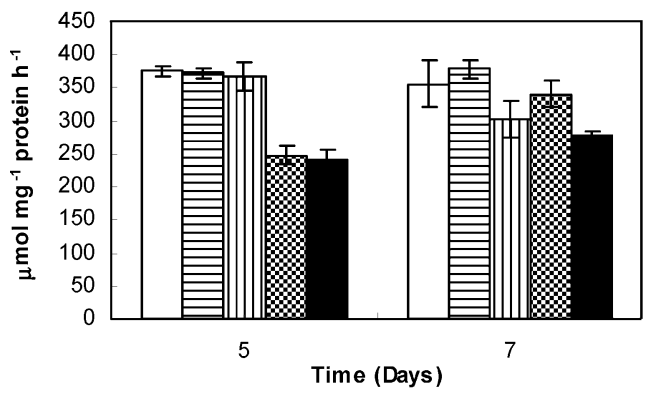

B
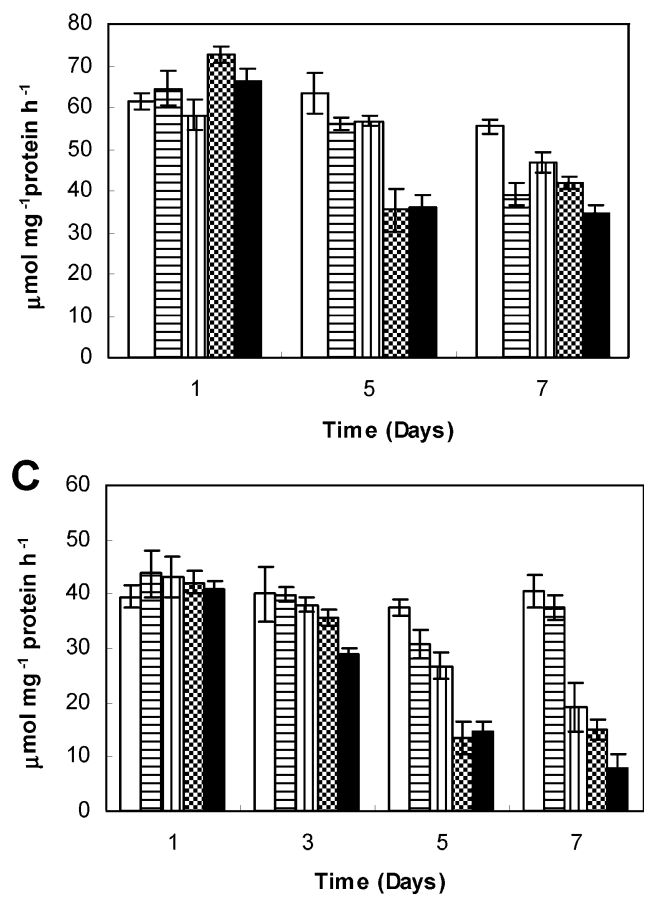

Figure 8. Nodule enzyme activities from lupine plants at 1-7 days after glyphosate treatments: (A) MDH; (B) AAT; (C) PEPC. Each value represents the average \pm SE of three to six determinations.

PEPC activity was inhibited by 35 and $53 \%$ in treatments of 5 and $10 \mathrm{mM}$, respectively. The inhibition of PEPC activity with 5 and $10 \mathrm{mM}$ treatments was continuous with time, whereas the lower treatments recovered at the end of the treatment. Interestingly, PEPC has a common substrate with EPSPS (the enzyme inhibited by glyphosate), PEP, which is the initial substrate for the shikimic acid pathway. In fact, glyphosate inhibition of EPSPS is competitive with respect to PEP. The high accumulation of shikimic acid is the result of a loss of feedback control of the first enzyme of the shikimic acid pathway by a downstream intermediate after EPSPS as discussed elsewhere. However, glyphosate itself did not have a direct effect on PEPC activity of maize incubated and assayed in vitro (i.e., $86 \%$ residual activity with $5 \mathrm{mM})(31)$. PEPC catalyzes the irreversible $\beta$-carboxylation of PEP by $\mathrm{HCO}_{3}{ }^{-}$in the presence of divalent cations to yield oxaloacetate and $\mathrm{P}_{\mathrm{i}}$. The enzyme PEPC fulfills critical roles in carbon metabolism during symbiotic $\mathrm{N}_{2}$ fixation by (i) supplying energy sources such as malate to bacteroids, (ii) supplying the carbon skeleton for the assimilation of fixed nitrogen, and (iii) recycling $\mathrm{CO}_{2}$ generated through respiration in both the legume and its bacteroids. Besides, PEPC is essential for the primary incorporation of $\mathrm{CO}_{2}$ in the photosynthetic process of $\mathrm{C}_{4}$ and CAM plants. In $\mathrm{C}_{3}$ plants
A

$\square$ Control $\boxminus 1.25 \mathrm{mM} \square 2.5 \mathrm{mM} \mathrm{⿴囗十} 5 \mathrm{mM}$

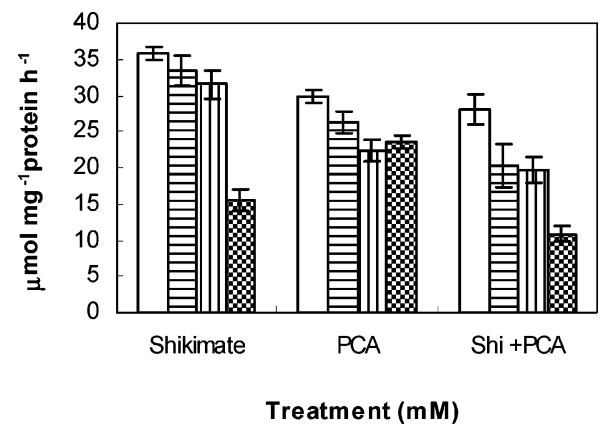

B

$\square 10 \mathrm{~min}$ : $20 \mathrm{~min}$ 曰30 min

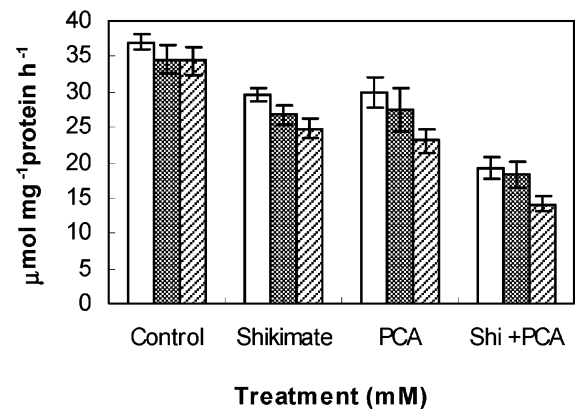

Figure 9. Effects of shikimate $(1.5,8,15$, and $30 \mathrm{mM})$ and/or protocatechuate $(5,7,10$, and $15 \mathrm{mM})$ found in nodules of glyphosatetreated plants on nodular PEPC activity of nontreated plants incubated for 10 min (A). Effects on PEPC activity of incubation time with shikimate $(15 \mathrm{mM})$ and/or protocatechuate $(10 \mathrm{mM})$ with extracts of nodules of nontreated plants $(B)$. Each value represents the average \pm SE of three to five determinations.

PEPC occurs in small amounts but also has a key position in $\mathrm{C} / \mathrm{N}$ metabolism (32). The activity of this central enzyme depends on its phosphorylation state, being more sensitive to activation of allosteric effectors (glucose 6-P) and less sensitive to allosteric inhibition by L-malate and shikimate (33). In fact, shikimate is a potent competitive inhibitor of PEPC of $\mathrm{C}_{4}$ Amaranthus viridis (14). Because glyphosate caused a great increase of shikimate in nodules (Figure 7A), the decrease of PEPC activity (Figure 8C) could be explained on the basis of a shikimate-mediated inhibition.

To assess the sensitivity of PEPC to varying concentrations of shikimate and PCA caused by glyphosate treatments, nodule extracts from nontreated plants were incubated and assayed in the presence of the same concentrations of shikimate and PCA found at 5 days in glyphosate-treated lupine nodules (Figure 9). The activity of PEPC was inhibited in a dose-dependent pattern by shikimate and PCA (Figure 9A), and the presence of both metabolites has an additive effect. To date, this is the first report indicating that PCA inhibits PEPC activity in vitro and could act as a regulator of PEPC activity in plants in coordination with other shikimic acid pathway derivates such as flavonoids and the shikimic acid itself (14). The incubation of the enzyme with both compounds increased the inhibition rate (Figure 9A). This suggests that inhibition in vivo could reach values higher than those found in the assayed nodule extracts.

Proposed Toxic Effect of Glyphosate on Nodules. From these findings, we propose a new mode of action to explain glyphosate toxicity in nodules, but a similar mechanism should occur in green tissues where shikimate accumulates (Figure 10). 


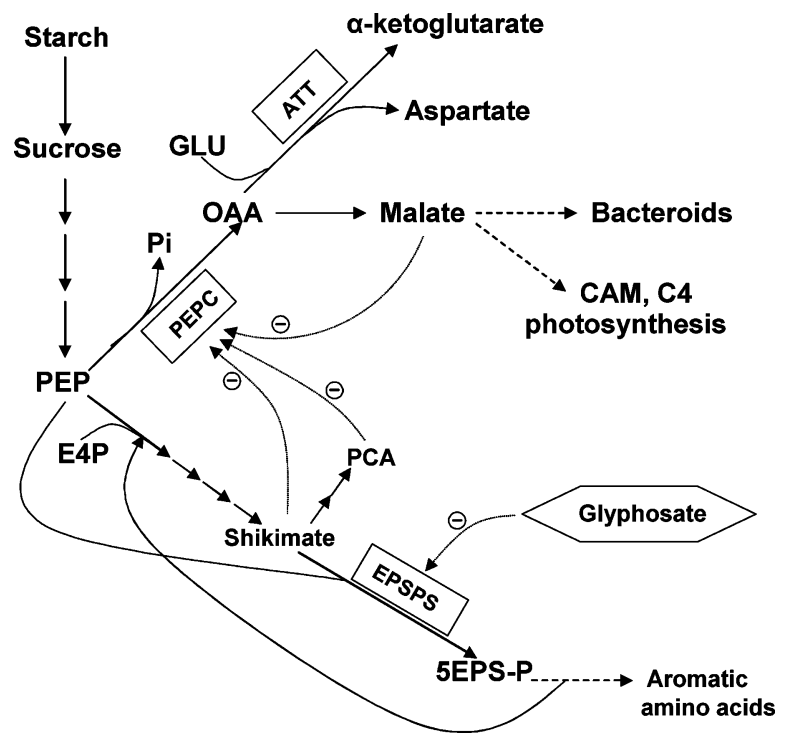

Figure 10. Scheme of proposed model of glyphosate action causing deregulation of the shikimate pathway and PEPC.

Inhibition of EPSPS by glyphosate causes an unregulated flow of erythrose 4-P and PEP as a result of a loss of feedback control of 3-deoxy-7-phospho-D-arabinoheptulosonate synthetase (EC 4.1.2.15), so shikimic acid and PCA accumulate rapidly to high levels, especially in metabolic sinks where the herbicide is continuously translocated. Shikimate and PCA could further inhibit PEPC activity of the nodule, decreasing oxaloacetate and malate production and availability for bacteroids metabolism, thus decreasing nitrogenase activity. This unique and effective mode of action of glyphosate should effectively block PEP diversion from the shikimate pathway, and most, if not all, PEP produced from sucrose will be channeled to the shikimate pathway and converted to the endogenous PEPC inhibitors, shikimate and PCA, reinforcing the inhibitory effect on PEPC. This double regulatory effect would exhaust most of the carbohydrate pool to form shikimate and protocatechuic acid in plant tissues.

The transient injury and inhibition of some plant and nodule parameters of glyphosate-resistant soybean $(8,12,34)$ and the susceptibility among varieties (12), could be related to the presence in these plants of the native glyphosate-sensitive EPSPS (27), which would contribute to increased shikimate levels and further affect PEPC before resistant EPSPS converts shikimate 3-phosphate on 5-enolpyruvylshikimate-3P and reestablishes background shikimate levels. However, in transgenic plants this accumulation should be low because, contrary to sensitive plants, PEP is also consumed to produce 5-enolpyruvylshikimate-3P downstream products by resistant EPSPS. In fact, in cultivars where this enzyme could be sufficiently expressed, no observed accumulation of shikimic should occur $(27,28)$. One similar effect could occur in other metabolic sinks such as leaves and reproductive structures, because glyphosateinduced shikimic acid accumulation was much higher in nonglyphsosate-resistant than in glyphosate-resistant cotton, but this response was less pronounced in reproductive tissues (27). Shikimate inhibition of PEPC could explain the loss of earlyseason cotton fruit (35) because PEPC is involved in fruit ripening (32) and plays a key role of PEPC during cotton fiber expansion (36).

PEPC inhibition by shikimate accumulation after glyphosate treatments could explain some unresolved tolerance of some species such as Conyza canadiensis L. Conq. not based in
EPSPS inhibition. In these glyphosate-resistant populations the initial shikimate concentration declined with time, but in the glyphosate-susceptible populations shikimate concentration increased with time (30). Due to the putative regulatory role proposed for shikimate controlling PEP partitioning between photosynthesis and the shikimate pathway in $\mathrm{C}_{4}$ plants (14) and the importance of PEPC in $\mathrm{C}_{4}, \mathrm{CAM}$, and also $\mathrm{C}_{3}$ plants, glyphosate could exert its toxic action further than its known direct action on the shikimate pathway. This study proposes an additional mechanism mediated by the endogenous PEPC inhibitors, shikimate and PCA, to explain the toxic effects of glyphosate in plants.

\section{ABBREVIATIONS USED}

AI, alkaline invertase; ARA, acetylene reduction activity; AAT, aspartate aminotranferase; DTT, dithiothreitol; DW, dry weight; EDTA, ethylenediaminetetraacetic acid; EPSPS, 5-enolpyruvylshikimic-3-phosphate synthase; FW, fresh weight; MDH, malate dehydrogenase; NAD, nicotinamide adenine dinucleotide; PBS, phosphate-buffered saline; PCA, protocatechuic acid; PEP, phosphoenolpyruvate; $\mathrm{PEPC}$, phosphoenolpyruvate carboxylase; PVPP, polyvinylpyrrolidone; SDS-PAGE, sodium dodecyl sulfate-polyacrylamide gel electrophoresis; SE, standard error; SS, sucrose synthase; UDP, uridine diphosphate; UDPG, uridine diphosphate-glucose.

\section{ACKNOWLEDGMENT}

We thank M. C. de Mesa and M. I. Menendez for technical assistance.

\section{LITERATURE CITED}

(1) Vance, C. P. Symbiotic nitrogen fixation and phosphorus acquisition, plant nutrition in a world of declining renewable resources. Plant Physiol. 2001, 127, 390-397.

(2) Duke, S. O.; Scheffler, B. E.; Dayan, F. E.; Dyer, W. E. Genetic engineering crops for improved weed management traits. ACS Symp. Ser. 2002, No. 829, 52-66.

(3) Reddy, K. N. Glyphosate-resistant soybean as a weed management tool: opportunities and challenges. Weed Biol. Manag. 2001, 1, 193-202.

(4) Zablotowicz, R. M.; Reddy, K. N. Impact of glyphosate on the Bradyrhizobium japonicum symbiosis with glyphosate-resistant transgenic soybean: a minireview. J. Environ. Qual. 2004, 33, 825-831.

(5) Fernández-Pascual, M. M.; Pozuelo, J. M.; Serra, M. T.; de Felipe, M. R. Effects of cyanazine and linuron on chloroplast development, nodule activity and protein metabolism in Lupinus albus L. J. Plant Physiol. 1988, 133, 288-294.

(6) Franz, J. E.; Mao, M. K.; Sikorski, J. A. Glyphosate: A Unique Global Herbicide; ACS Monograph 189; American Chemical Society: Washington, DC, 1997.

(7) Duke, S. O.; Rimando, A. M.; Pace, P. F.; Reddy, K. N.; Smeda, R. J. Isoflavone, glyphosate, and aminomethylphosphonic acid levels in seeds of glyphosate-treated, glyphosate-resistant soybean. J. Agric. Food Chem. 2003, 51, 340-344.

(8) Reddy, K. N.; Zablotowicz, R. M. Glyphosate-resistant soybean response to various salts of glyphosate and glyphosate accumulation in soybean nodules. Weed Sci. 2003, 51, 496-502.

(9) Becerril, J. M.; Duke, S. O.; Lydon, J. Glyphosate effect on shikimate pathway products in leaves and flowers of velvetleaf. Phytochemistry 1989, 28, 695-699.

(10) Hernández, A.; García-Plazaola, J. I.; Becerril, J. M. Glyphosate effects on phenolic metabolism of nodulated soybean (Glycine max L. Merr.). J. Agric. Food Chem. 1999, 47, 2920-2925.

(11) Lydon, J.; Duke, S. O. Glyphosate induction of elevated levels of hydroxybenzoics acids in higher plants. J. Agric. Food Chem. 1988, 36, 813-818. 
(12) King, A. C.; Purcell, L. C.; Vories, E. D. Plant growth and nitrogenase activity of glyphosate-tolerant soybean in response to glyphosate applications. Agron. J. 2001, 93, 179-186.

(13) Moorman, T. B.; Becerril, J. M.; Lydon, J.; Duke, S. O. Production of hydroxybenzoic acids by Bradyrhizobium japonicum strains after treatment with glyphosate. J. Agric. Food Chem. 1992, 40, 289-293.

(14) Colombo, S. L.; Andreo, C. S.; Chollet, R. The interaction of shikimic acid and protein phosphorilation with PEP carboxylase from the C4 dicot Amaranthus viridis. Phytochemstry 1998, 48, $55-59$.

(15) Zhang, X. Q.; Chollet, R. Phosphoenolpyruvate carboxylase protein kinase from soybean root nodules: partial purification, characterization, and up/down-regulation by photosynthate supply from shoots. Arch. Biochem. Biophys. 1997, 343, 260-268.

(16) Lang, P.; Martín, R.; Golvano, M. P. Effect of nitrate on carbon metabolism and nitrogen fixation in lupin root nodules Lupinus albus L. cv. Multolupa. Plant Physiol. Biochem. 1993, 31, 639648.

(17) Gordon, A. J.; Minchin, F. R.; James, C. L.; Komina, O. Sucrose synthase in legume nodules is essential for nitrogen fixation. Plant Physiol. 1999, 120, 867-877.

(18) Carpena, R. O.; Vázquez, S.; Esteban, E.; Fernández-Pascual, M.; de Felipe, M. R.; Zornoza, P. Cadmium-stress in white lupin: effects on nodule structure and functioning. Plant Physiol. Biochem. 2003, 41, 911-919.

(19) Guasch, L. M.; de Felipe, M. R.; Fernández-Pascual, M. Effects of different $\mathrm{O}_{2}$ concentrations on nitrogenase activity, respiration, and $\mathrm{O}_{2}$ diffusion resistance in Lupinus albus L. cv. Multolupa nodules. J. Plant Physiol. 2001, 158, 1395-1402.

(20) Arrese-Igor, C.; González, E. M.; Gordon, A. J.; Gálvez, L.; Royuela, M.; Cabrerizo, P. M.; Aparicio-Tejo, P. M. Sucrose synthase and nodule nitrogen fixation under drought and other enviroment stresses. Symbiosis 1999, 27, 189-212.

(21) Servaites, J. C.; Tucci, M. A.; Geiger, D. R. Glyphosate effects on carbon assimilation, ribulose bisphosphate carboxylase activity, and metabolite levels in sugar beets leaves. Plant Physiol. 1987, 85, 370-374.

(22) Su, L. Y.; DelaCruz, A.; Moore, P. H.; Maretzki, A. The relationship of glyphosate treatment to sugar metabolism in sugarcane: new physiological insights. J. Plant Physiol. 1992, 140, 168-173.

(23) Shieh, W.-J.; Geiger, D. R.; Servaites, J. C. Effect of $N$ (phosphonomethyl) glycine on carbon assimilation and metabolism during a simulated natural day. Plant Physiol. 1991, 97, $1109-1114$

(24) Gonzalez, E.; Aparicio-Tejo, P. M.; Gordon, A.; Minchin, F. R.; Royuela, M.; Arrese-Igor, C. Water-deficit on carbon and nitrogen metabolism of pea nodules. J. Exp. Bot. 1998, 49, $1705-1714$
(25) Pozueta-Romero, J.; Perata, P.; Akazawa, T. Sucrose-starch conversion in heterotrophic tissues of plants. Crit. Rev. Plant Sci. 1999, 18, 489-525.

(26) Haslam, E. Introduction, commentary, and overview. In Shikimic Acid: Metabolims and Metabolites; Haslam, E., Ed.; Wiley: New York, 1993; pp 1-16.

(27) Pline, W. A.; Wilcut, J. W.; Duke, S. O.; Edmisten, K. L.; Wells, $\mathrm{R}$. Tolerance and accumulation of shikimic acid in response to glyphosate applications in glyphosate-resistant and nonglyphosate-resistant cotton (Gossypium hirsutum L.). J. Agric. Food Chem. 2002, 50, 506-512.

(28) Singh, B. K.; Shaner, D. L. Rapid determination of glyphosate injury to plants and identification of glyphosate-resistant plants. Weed Technol. 1998, 12, 527-530.

(29) Bresnahan, G. A.; Manthey, F. A.; Howatt, K. A.; Chakraborty, M. Glyphosate applied preharvest induces shikimic acid accumulation in hard red spring wheat (Triticum aestivum). $J$. Agric. Food Chem. 2003, 51, 4004-4007.

(30) Mueller, T. C.; Massey, J. H.; Hayes, R. M.; Main, C. L.; Stewart, C. N. Shikimate accumulates in both glyphosate-sensitive and glyphosate-resistant horseweed (Conyza canadiensis L. Cronq.) J. Agric. Food Chem. 2003, 51, 680-684.

(31) Podesta, F. E.; Gonzalez, D. H.; Andreo, C. S. Glyphosine inhibits maize leaf phosphoenolpyruvate carboxylase. Plant Cell Physiol. 1987, 28, 375-378.

(32) Chlollet, R.; Vidal, J.; O’Leary, M. H. Phosphoenolpyruvate carboxylase: a ubiquitous, highly regulated enzyme in plants. Annu. Rev. Plant Phys. Plant Mol. Biol. 1996, 47, 273-298.

(33) Xu, W.; Zhou, Y.; Chollet, R. Identification and expression of a soybean nodule-enhanced PEP-carboxylase kinase gene (NEPpck) that shows striking up-/down-regulation in vivo. Plant $J$. 2003, 34, 441-452.

(34) Reddy, K. N.; Hoagland, R. E.; Zablotowicz, R. M. Effect of glyphosate on growth, chlorophyll content and nodulation in glyphosate-resistant soybean (Glycine max) varieties. J. New Seeds 2000, 2, 37-52.

(35) Jones, M. A.; Snipes, C. E. Tolerance of transgenic cotton to tropical applications of glyphosate. J. Cotton Sci. 1999, 3, 1926.

(36) Vojdani, F.; Kim, W.; Wilkins T. A. Phosphoenolpyruvate carboxylase cDNAs from developing cotton (Gossypium hirsutum) fibers. (Accession Nos. AF008939 and AF008940) (PGR97135). Plant Physiol. 1997, 115, 315.

Received for review October 25,2005 . Revised manuscript received January 10, 2006. Accepted January 11, 2006. The work was supported by Comunidad de Castilla-La Mancha Project 168/CH-47. N.d.M. was funded by a CCLM Ph.D. studentship within the same project.

JF058166C 